Bài báo khoa học

\title{
Xác định đỗ lỗ rỗng hữu hiệu tầng chứa nước Pleistocen khu vụ̣c huyện Cẩm Giàng, tỉnh Hải Dương bằng phương pháp thực nghiệm và mô hình số
}

\author{
Hoàng Văn Duy ${ }^{1}$, Nguyễn Trung Hiếu ${ }^{2}$, Tống Thanh Tùng ${ }^{3}$, Đoàn Thu Hà ${ }^{*}$ \\ ${ }^{1}$ Viện Khoa học Tài nguyên nước; hoangduydctv@gmail.com; \\ 2 Trường Đại học Thủy lợi; trunghieu.ma@hotmail.com; \\ ${ }^{3}$ Liên đoàn quy hoạch và điều tra tài nguyên nước miền Bắc; thanhtungtv51@gmail.com; \\ ${ }^{4}$ Trường Đại học Thủy lợi; thuha_ctn@tlu.edu.vn \\ *Tác giả liên hệ: thuha_ctn@tlu.edu.vn; Tel.: +84-948172299
}

Ban Biên tập nhận bài: 12/5/2021; Ngày phản biện xong: 29/7/2021; Ngày đăng bài: $25 / 10 / 2021$

Tóm tắt: Độ lỗ hổng hữu hiệu $\left(\mathrm{n}_{0}\right)$ là một trong những thông số địa chất thủy văn chuyên môn quan trọng, có ý nghĩa xác định mức độ lan truyển nhanh hay chậm các vật chất gây ô nhiễm, nhiềm mặn trong nước dưới đất. Khu vực Hải Dương với mức độ mặn nhạt nước dưới đất đan xen nhau rất phức tạp, lưu lượng khai thác nước dưới đất tăng lên theo thời gian, là nguyên nhân gây xâm nhập mặn, đã được lựa chọn là khu vực nghiên cứu. Sử dụng phương pháp thí nghiệm bơm nước và ép dung dịch muối ở gần ranh giới mặn-nhạt nước dưới đất và bằng cách sử dụng mô hình Modflow và MT3D đã xác định được độ lỗ hổng hữu hiệu tầng Pleistocen ( $\left.\mathrm{qp}_{1}\right)$ tại khu vực xã Cẩm Hoàng, huyện Cẩm Giàng, tỉnh Hải Dương bằng 0,23 .

Từ khoá: Nhiễm mặn; Hút nước thí nghiệm; Dung dịch chất chỉ thị; Độ lỗ rỗng hữu hiệu; Mô hình số.

\section{1. Đặt vấn đề}

Một trong các thông số địa chất thuỷ văn quan trọng cần được xác định khi điều tra đánh giá tài nguyên nước dưới đất là độ lỗ hổng hưuu hiệu $\left(\mathrm{n}_{0}\right)$, đó là phần lỗ hổng của đất đá chứa nước có khả năng cho nước đi qua. Nghiên cứu xác định được độ lỗ hổng hữu hiệu có ý nghĩa quan trọng trong việc tính toán dịch chuyển của ranh giới mặn nhạt của tầng chứa nước, tính toán khả năng lan truyền vật chất trong môi trường nước dưới đất nhằm đánh giá khả năng, tốc độ nhiễm bẩn. Khu vực thành thành phố Hải Dương, nơi nước dưới đất có nguy cơ xâm nhập mặn và nhiễm bẩn rất cao, việc nghiên cứu xác định độ lỗ hổng hữu hiệu là việc làm không thể thiếu khi điều tra địa chất thuỷ văn nhằm đánh giá tài nguyên nước dưới đất.

Xác định độ lỗ hổng hữu hiệu được thực hiện bằng các thí nghiệm tại thực địa và chính lý tính toán văn phòng bằng các phương pháp khác nhau. Vùng Hải Dương đã thưc hiện thí nghiệm ở cụm lỗ khoan thí nghiệm CHD3 gần ranh giới mặn nhạt của tầng chứa nước pleistocen (qp) tại xã Cẩm Hoàng, huyện Cẩm Giàng (Hình 1). Chất chỉ thị là muối ăn $(\mathrm{NaCl})$ được ép vào 1 lỗ khoan, tiến hành bơm nước ở lỗ khoan khác. Việc chỉnh lý xác định độ lỗ hổng hữu hiệu thực hiện bằng phương pháp mô hình số.

Nước dưới đất (NDĐ) khu vực Hải Dương được khai thác phục vụ các nhu cầu kinh tế xã hội của khu vực từ xa xưa, tuy nhiên mức độ mặn nhạt đan xen phức tạp và do ảnh hưởng của việc khai thác ngày càng tăng đang làm tăng nguy cơ xâm nhặp mặn. Cùng với thời gian 
khai thác, diện tích phễu hạ thấp mực nước toàn vùng ngày càng mở rộng và tiến gần đến ranh giới mặn nhạt của tầng chứa nước Pleistocen ở khu vực xã Cẩm Hoàng, huyện Cẩm Giàng, Tỉnh Hải Dương [1-6]. Chất chỉ thị muối ăn $(\mathrm{NaCl})$ được ép vào cụm lỗ khoan thí nghiệm $\mathrm{CHD} 3$ nhằm xác định độ lỗ rỗng hữu hiệu $n_{0}$, là thông số ảnh hưởng đến sự lan truyền vật chất trong nước dưới đất và cần thiết phải có thể xây dựng mô hình dự báo quá trình dịch chuyển ranh giới mặn nhạt nước dưới đất về phía trung tâm huyện Cẩm Giàng là theo hướng dòng chảy. Sơ đồ ranh giới mặn nhạt tầng chứa nước Pleistocen $\left(\mathrm{qp}_{1}\right)$ thể hiện trên Hình 1 .

Nghiên cứu này trình bày phương pháp xác định độ lỗ rỗng hữu hiệu bằng phương pháp thí nghiệm ngoài thực địa ở khu vực gần ranh giới mặn nhạt NDĐ tầng qp 1 tại xã Cẩm Hoàng, huyện Cẩm Giàng, Tỉnh Hải Dương, sau đó chỉnh lý tính toán bằng phương pháp mô hình số sử dụng mô hình Modflow và MT3D.

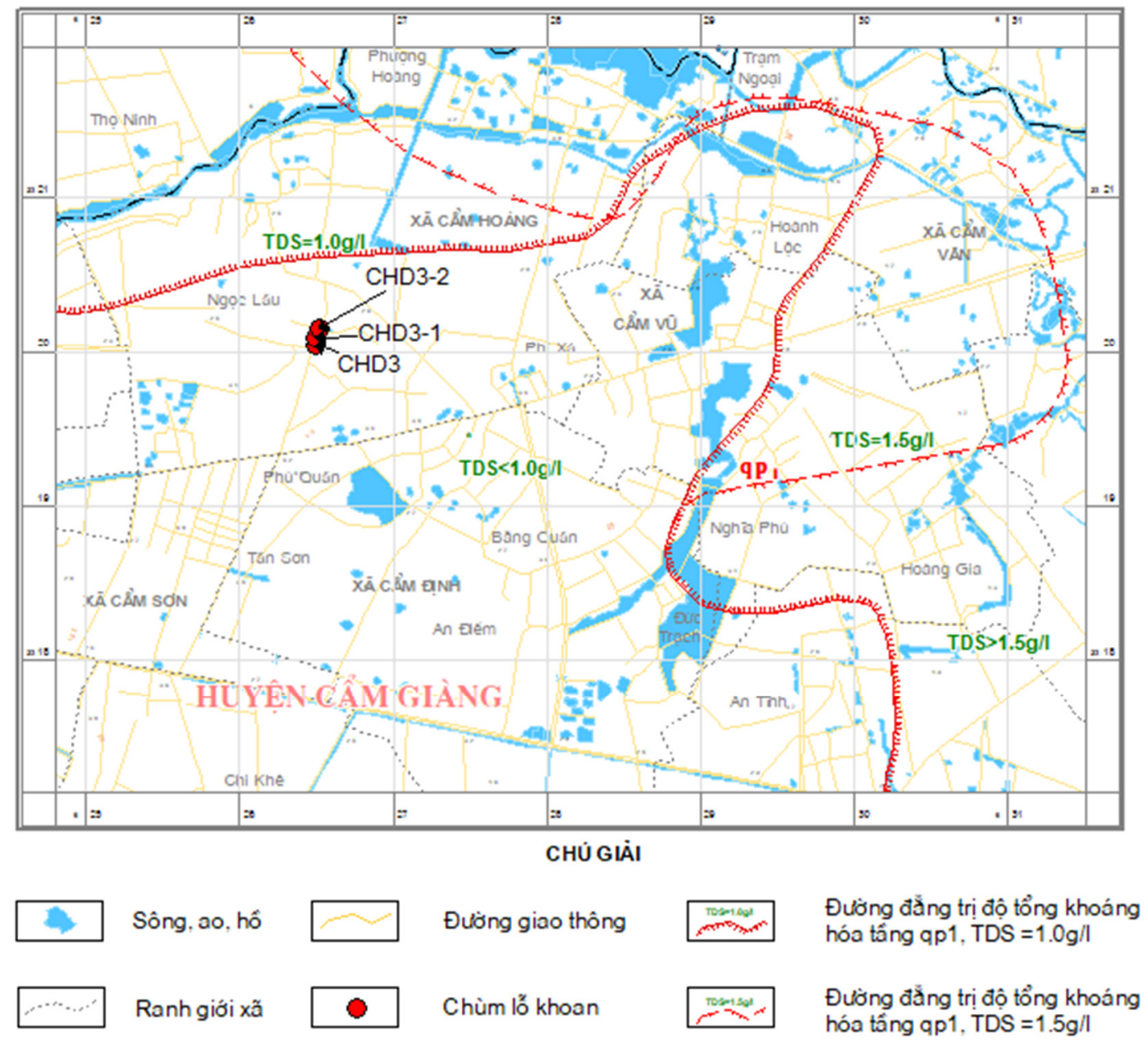

Hình 1. Sơ đồ vị trí cụm thí nghiệm ngoài thực địa.

\section{Phương pháp nghiên cứu và số liệu thu thập}

\subsection{Giới thiệu về khu vưc nghiên cúu}

Với đặc điểm địa chất thủy văn ở vùng Hải Dương, kết hợp với nhu cầu khai thác ngày càng tăng, diễn biễn về chất lượng nước và ranh giới mặn nhạt phức tạp. Nghiên cứu xác định độ lỗ hổng hữu hiệu $\left(\mathrm{n}_{0}\right)$ được thực hiện sử dụng hệ giếng có sẵn thuộc thôn Ngọc Lâu, xã Cẩm Hoàng, huyện Cẩm Giàng, tỉnh Hải Dương. Sơ đồ vị trí cụm thí nghiệm ngoài thực địa được thể hiện trên Hình 1 . Độ lỗ hổng hữu hiệu $\left(\mathrm{n}_{0}\right)$ được xác định cho tầng chứa nước khu vực gần ranh giới mặn nhạt NDĐ tầng $\mathrm{qp}_{1}$. Cấu trúc địa chất thủy văn tại địa điểm nghiên cứu được thể hiện trên Hình 2 [1-11]. 


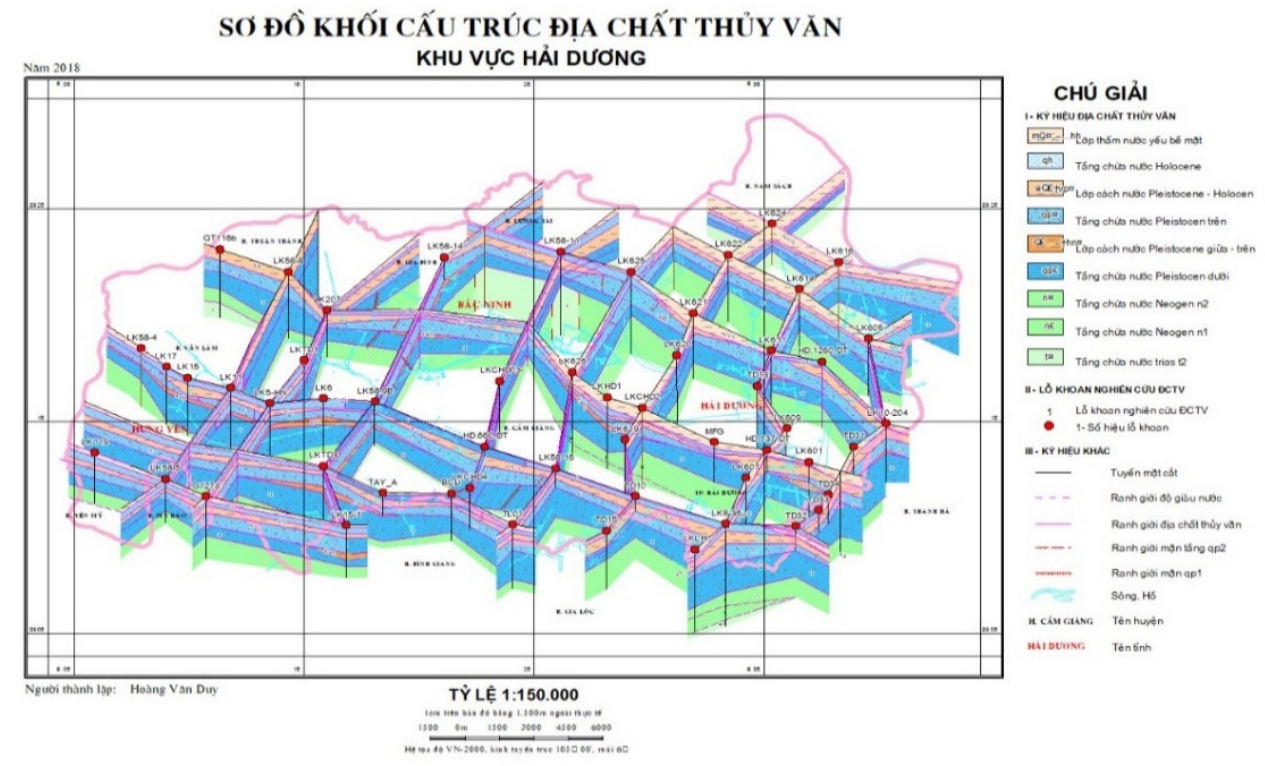

Hình 2. Sơ đồ cấu trúc địa chất thủy văn khu vực Hải Dương.

\subsection{Co' sở khoa hoc}

Phương trình lan truyền vật chất mô tả cơ chế dịch chuyển (đối lưu) và phân tán thủy động lực của NDĐ có hướng dòng chảy chính theo phương $x$ trong không gian một chiều $(x$, y) được viết [7-8]:

$$
\mathrm{D}_{\mathrm{x}} \frac{\partial^{2} \mathrm{C}}{\partial \mathrm{x}^{2}}-\mathrm{U}_{\mathrm{x}} \frac{\partial \mathrm{C}}{\partial \mathrm{x}}=\mathrm{R} \frac{\partial \mathrm{C}}{\partial \mathrm{t}}
$$

Trong đó $\mathrm{D}_{\mathrm{x}}$ là hệ số phân tán thủy động lực học theo hướng $\mathrm{x}\left(\mathrm{L}^{2} / \mathrm{T}\right)$; $\mathrm{C}$ là nồng độ chất hoà tan trong nước $\left(\mathrm{M} / \mathrm{L}^{3}\right) ; \mathrm{U}_{\mathrm{x}}\left(\mathrm{U}=\mathrm{V} / \mathrm{n}_{\mathrm{hh}}\right)$ vận tốc thực của dòng nước tương ứng theo hướng $\mathrm{x}$ và $\mathrm{y}(\mathrm{M} / \mathrm{T}) ; \mathrm{V}$ là vận tốc Đắc-xi; $\mathrm{n}_{\mathrm{h}}$ là độ lỗ rỗng hữu hiệu; $\mathrm{R}$ là hệ số chậm trễ; $\mathrm{t}$ là thời gian $(\mathrm{T})$.

Hệ số phân tán thuỷ động lực xác định theo công thức sau [7-15]:

$$
\mathrm{D}_{\mathrm{x}}=\mathrm{D}^{\prime}{ }_{\mathrm{x}}+\mathrm{D}_{\mathrm{d}}^{*} ; \mathrm{D}_{\mathrm{x}}=\mathrm{a}_{\mathrm{L}} \mathrm{U}
$$

Trong đó $\mathrm{D}_{\mathrm{x}}{ }_{\mathrm{x}}$ là hệ số phân tán cơ học tương ứng theo hướng $\mathrm{x}$ và $\mathrm{y}\left(\mathrm{L}^{2} / \mathrm{T}\right) ; \mathrm{D}^{*}{ }_{\mathrm{d}}$ là hệ số khuếch tán phân tử trong môi trường rỗng $\left(\mathrm{L}^{2} / \mathrm{T}\right)$; $\mathrm{a}_{\mathrm{L}}$ là độ phân tán dọc.

Phương trình (1) chỉ có lời giải duy nhất khi có đầy đủ các điều kiện ban đầu và điều kiện biên được mô tả như sau:

Điều kiện ban đầu là phân bố nồng độ của vật chất đang xem xét vào thời điểm ban đầu tùy ý $\mathrm{t}=\mathrm{t}_{0}$ tại mọi vị trí trong miền tính toán:

$$
\mathrm{c}=\mathrm{c}_{\mathrm{o}}(\mathrm{x}, \mathrm{y})
$$

Các điều kiện biên có thể là một hoặc đồng thời các dạng sau:

- Biên có nồng độ đã biết:

$$
\mathrm{C}=\mathrm{C}_{\mathrm{c}} \text { trên } \Gamma_{\mathrm{c}}
$$

- Biên có gradient nồng độ pháp tuyến với đường biên đã biết (biên Neumann):

$$
\mathrm{D}_{\mathrm{xy}} \frac{\partial \mathrm{c}}{\partial \mathrm{n}}+\mathrm{V}_{\mathrm{n}}\left(\mathrm{c}_{\mathrm{q}}-\mathrm{c}\right)=\mathrm{q}_{\mathrm{c}} \text { trên } \Gamma_{\mathrm{q}_{\mathrm{c}}}
$$

- Biên có dòng vật chất khuếch tán-lôi cuốn pháp tuyến với biên đã biết (biên Cauchi): 


$$
\mathrm{V}_{\mathrm{n}} \mathrm{C}-\mathrm{D}_{\mathrm{n}} \frac{\partial \mathrm{C}}{\partial \mathrm{n}}=\frac{\mathrm{V}_{0} \mathrm{C}_{\mathrm{v}}}{\mathrm{n}} \text { trên biên } \Gamma_{\mathrm{q}_{\mathrm{uc}}}
$$

Trong đó $\mathrm{V}_{0}, \mathrm{C}_{\mathrm{v}}$ tương ứng là dòng nước và nồng độ chất hoà tan trong nước qua biên.

\subsection{Phương pháp nghiên cúu}

\subsubsection{Phương pháp mô hình hoá xác định các thông số lan truyền}

Đối với trường hợp hút nước từ $L K$ trung tâm và ép dung dịch vào $L K$ ở gần miền lan truyền có các cơ chế lan truyền chính [11] thể hiện trên hình 3.

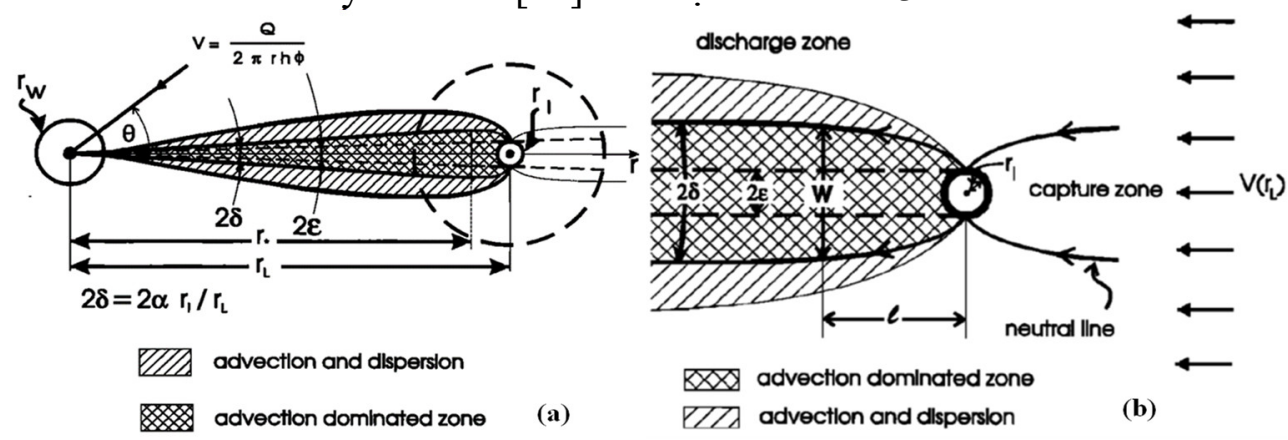

Hình 3. Hai miền có cơ chế lan truyền chính trong thí nghiệm hút nước và ép chất chỉ thị.

Chiều rộng $\mathrm{W}$ của đới thu nước từ phía thượng lưu dòng chảy vào $\mathrm{LK}$ ép nước và đới cấp nước từ LK ép nước cho đới hạ lưu dòng chảy [20] có giá trị $\mathrm{W} \leq 4 \mathrm{r}_{\text {I }}$ nếu hệ số thấm phần xung quanh LK nhỏ hơn hệ số thấm của tầng chứa nước. Trong thí nghiệm cho chúng ta nồng độ chất chỉ thị trong NDĐ trong LK hút nước, trong khi đó mô hình một chiều theo tuyến đi qua LK hút nước và ép nước lại chỉ cho kết quả nồng độ chất chỉ thị tại rìa LK hút nước. Vì vậy có thể sử dụng nồng độ tươngđối có dạng thể hiện trên hình 1 đối với nồng độ chất chỉ thị quan trắc được trong LK hút nước và nồng độ chất chỉ thị xác định theo mô hình một chiều. Như vậy hai đường cong phân bố nồng độ tương đối này trong $L K$ hút nước và tại điểm mép LK hút nước của mô hình một chiều về mặt lý thuyết là trùng nhau. Nếu ký hiệu nồng độ chất chỉ thị nước $L K$ hút nước là $C_{L K V O ̛ ́}$ giá trị cực đại là $C_{L K m a x}$ và cực tiểu $\mathrm{C}_{\mathrm{LKmin}}$ và nồng độ xác định theo mô hình một chiều tại mép $\mathrm{LK}$ hút nước là $\mathrm{C}_{1 \mathrm{D}}$ với giá trị cực đại là $C_{1 D m a x}$ và cực tiểu $C_{1 D m i n}$ ta có nồng độ tương đối $L K$ hút nước và mép $L K$ hút nước của mô hình một chiều như sau:

$$
\mathrm{C}=\frac{\mathrm{C}_{L K}-\mathrm{C}_{L K \min }}{\mathrm{C}_{\mathrm{LKmax}}-\mathrm{C}_{\mathrm{LK} \min }} ; \quad \mathrm{C}=\frac{\mathrm{C}_{1 \mathrm{D}}-\mathrm{C}_{1 \mathrm{D} \min }}{\mathrm{C}_{1 \mathrm{D} \max }-\mathrm{C}_{1 \mathrm{D} \min }}
$$
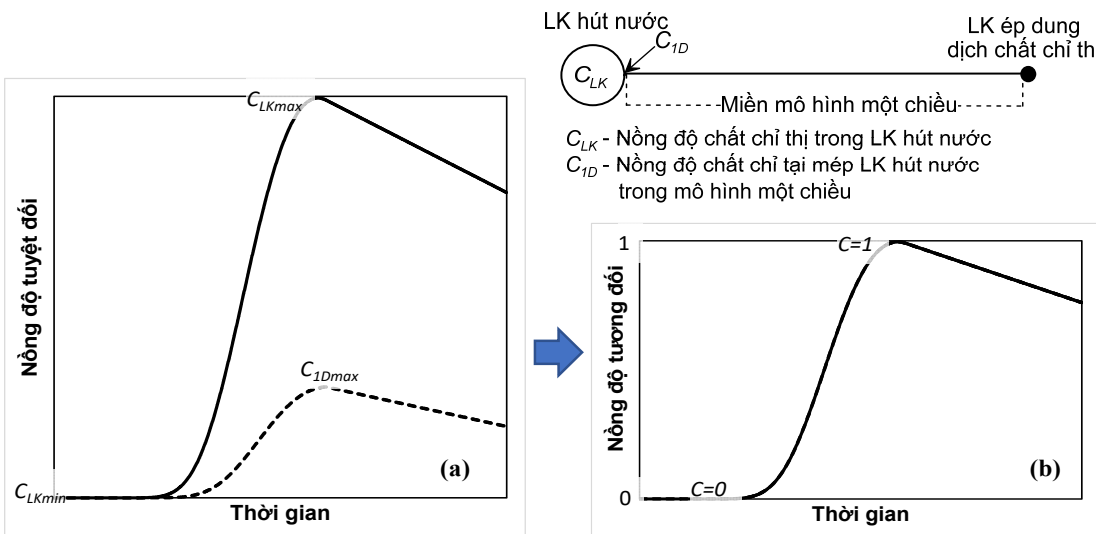

Hình 4. Nồng độ tuyệt đối (a) và tương đối (b) NDĐ trong LK hút nước mép LK hút nước trong mô hình một chiều. 


\subsubsection{Sơ đồ thí nghiệm}

Sơ đồ thí nghiệm gồm ba lỗ khoan gồm lỗ khoan trung tâm CHD3 là lỗ khoan hút nước và hai lỗ khoan quan sát kết hợp ép dung dịch chất chỉ thị là $\mathrm{CHD} 3-1$ và $\mathrm{CHD} 3-2$ tạo thành 1 tuyến cách đều nhau $8 \mathrm{~m}$ (Hình 5). Dung dịch chỉ thỉ được sử dụng là muối $\mathrm{NaCl}$.

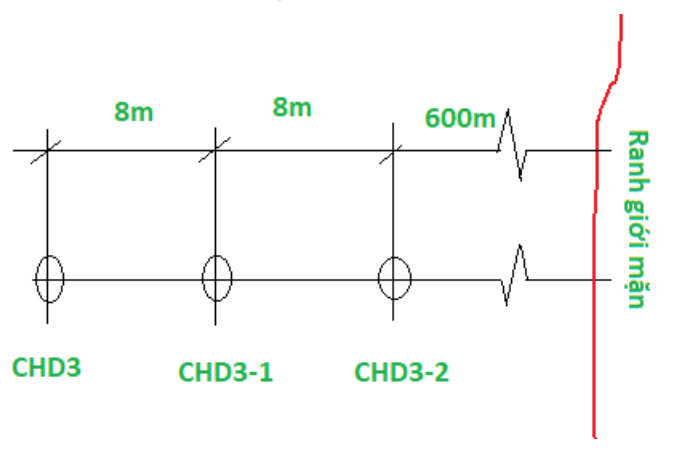

Hình 5. Sơ đồ vị trí các lỗ khoan thí nghiệm.

Lỗ khoan hút nước có đường kính trong là $168 \mathrm{~mm}$, lỗ khoan ép dung dịch chất chỉ thị có đường kính trong là $90 \mathrm{~mm}$. Thời gian hút nước và ép dung dịch thí nghiệm là $168 \mathrm{~h}$. Hút nước và ép dung dịch muối được bắt đầu cùng một lúc. Lưu lượng hút nước là $705 \mathrm{~m} / \mathrm{ngày}$ $(8,15 \mathrm{l} / \mathrm{s})$, lưu lượng ép dung dịch chất chỉ thị là $43,2 \mathrm{~m}^{3} /$ ngày $(0,5 \mathrm{l} / \mathrm{s})$.

Nồng độ chất chỉ thị được xác định qua công thức biểu diễn mối tương quan giữa nồng độ muối ăn và độ dẫn điện được qui đổi ra ở điều kiện nhiệt độ bằng $25^{\circ} \mathrm{C}$. Độ tổng khoáng hoá của NDĐ tự nhiên là $0,7 \mathrm{~g} / 1$, nồng độ muối ăn được hoà vào NDĐ là $5 \mathrm{~g} / 1$ tạo nên dung dịch có độ tổng khoáng hoá $5,71 \mathrm{~g} / 1$ dùng để ép vào lỗ khoan. Sau khi hút nước thí nghiệm gần đạt trạng thái ổn định và bắt đầu ép muối vào lỗ khoan quan sát $\mathrm{CHD} 3-1$. Nước trong lỗ khoan ép dung dịch luôn được xáo trộn bởi ống ép dung dịch thường xuyên nâng lên và hạ xuống trong toàn bộ chiều dày cột nước trong lỗ khoan. Đầu đo độ dẫn điện tự động được đặt ở giữa tầng chứa nước [1].

\section{Kết quả nghiên cứu và thảo luận}

\subsection{Kết quả chỉnh lý mô hình dòng chảy nước duới đất tại khu vực nghiên cưu}

\subsubsection{Nhập dữ liệu về lưới và bước lưới trong mô hình}

Dựa vào bán kính ảnh hưởng của lỗ khoan hút nước thí nghiệm tại chùm thí nghiệm CHD3 đã xác lập diện tích vùng lập mô hình là $16 \mathrm{~km}^{2}$. Chia toàn bộ vùng nghiên cứu thành các ô lưới với số lượng 40 hàng và 36 cột (Hình 6). Kích thước ô lưới là $1 \times 1 \mathrm{~m}$ phù hợp để chạy bài toán dịch chuyển vật chất.

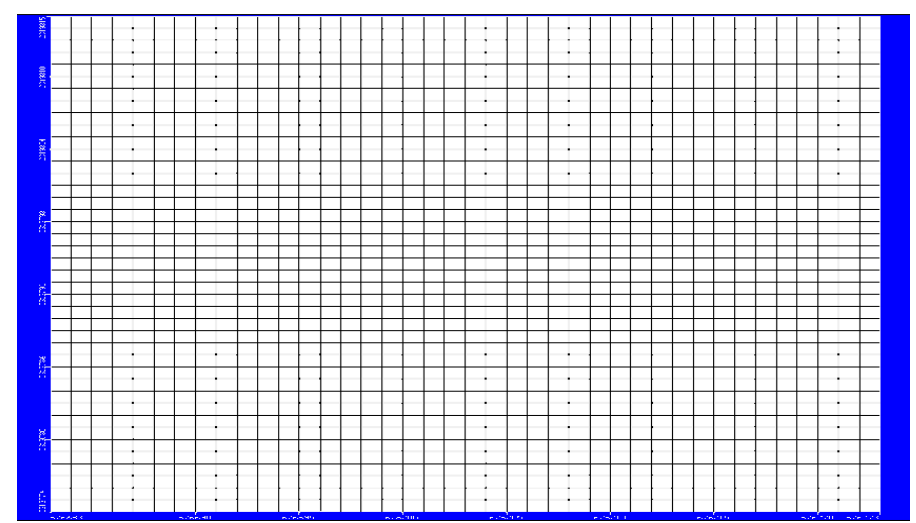

Hình 6. Thiết kế lưới sai phân trên diện tích vùng nghiên cứu. 
3.1.2. Nhập dữ liệu về phân tầng địa chất thủy văn

Dựa trên mặt cắt và cột địa tầng lỗ khoan tại chùm thí nghiêm đã xây dựng được mô hình cấu trúc địa chất thủy văn gồm 7 lớp làm nền tảng để xây dựng mô hình dòng chảy cũng như mô hình dịch chuyển chất bẩn.

- Lớp 1: Lớp thấm nước yếu bề mặt (LCNBM)

- Lớp 2: Tầng chứa nước lỗ hổng trong các trầm tích Holocene (qh)

- Lớp 3: Lớp cách nước thuộc hệ tầng Vĩnh Phúc $\mathrm{aQ}_{1}{ }^{3} v p_{2}$ (LCNVP).

- Lớp 4: Tầng chứa nước lỗ hổng trong các trầm tích Pleistocene trên (qpap).

- Lớp 5: Lớp cách nước thuộc hệ tầng Hà Nội Q ${ }_{1}^{2-3} h n_{2}$ (LCNHN).

- Lớp 6: Tầng chứa nước lỗ hổng trong các trầm tích Pleistocene dưới ( $\left.\mathrm{qp}_{1}\right)$.

- Lớp 7: Lớp cách nước thuộc hệ tầng Vĩnh Bảo $\mathrm{N}_{2} v b_{2}$ (LCNVB).

\subsubsection{Nhập dữ liệu về các thông số địa chất thủy văn}

Các thông số địa chất thủy văn của các tầng chứa nước chủ yếu dựa theo tài liệu hút nước thí nghiệm ở chùm $\mathrm{CHD} 3$ và ở giai đoạn trước tính toán theo điều kiện vận động không ổn định nhờ phần mềm Aquifer Test, có kết quả như Bảng 1 [1].

Bảng 1. Thông số địa chất thủy văn của các tầng chứa nước.

\begin{tabular}{cccccc}
\hline TT & $\begin{array}{c}\text { Số hiệu lỗ } \\
\text { khoan }\end{array}$ & $\begin{array}{c}\text { Hệ số dẫn nước } \\
\left(\mathbf{K m}, \mathbf{~ m}^{\mathbf{2}} / \mathbf{n g a ̀ y}\right)\end{array}$ & $\begin{array}{c}\text { Hệ số thấm } \\
(\mathbf{K}, \mathbf{m} / \mathbf{n g a ̀ y})\end{array}$ & $\begin{array}{c}\text { Hệ số nhả nước } \\
\text { đàn hồi }(\boldsymbol{\mu} *)\end{array}$ & $\begin{array}{c}\text { Ghi } \\
\text { chú }\end{array}$ \\
\hline 1 & CHD3 & 1520 & 152 & 0,234 \\
2 & CHD3-1 & 1410 & 141 & 0,143 \\
3 & CHD3-2 & 1450 & 145 & 0,0114 \\
\hline
\end{tabular}

3.1.4. Nhập dữ liệu về điều kiện biên mô hình

- Biên bổ cập (RECHARGE): Lượng bổ cập cho nước ngầm tại thời điểm bơm chùm thí nghiệm bằng 0 .

- Biên bốc hơi (Evapo): Lượng bốc hơi tại thời điểm bơm chùm thí nghiệm bằng 0 .

- Biên mực nước (CHD) được gán cho tầng các chứa nước $\mathrm{qh}, \mathrm{qp}_{2}, \mathrm{qp}_{1}$. Trị số mực nước trên các biên này được xác định theo tài liệu lỗ khoan quan sát CHD3-2.

3.1.5. Nhập dữ liệu về hiện trạng khai thác: Coi lỗ khoan hút nước là công trình khai thác nước có công suất là $705 \mathrm{~m}^{3} /$ ngày.

3.1.6. Nhập dữ liệu về mực nước ban đầu: Dữ liệu mực nước ban đầu được lựa chọn tại thời điểm trước trước khi bơm chùm thí nghiệm.

\subsection{Chỉnh lý và đánh giá sai số của mô hình}

\subsubsection{Kết quả chỉnh lý mô hình dòng chảy nước dưới đất}

Để chỉnh lý mô hình theo bài toán ổn định được tiến hành dựa theo tài liệu quan trắc mực nước thực tế tại các các lỗ khoan quan sát. Mức độ tin cậy của mô hình được xác định qua sai số mực nước giữa mô hình và lỗ khoan quan sát thực tế. Kết quả chính lý mô hình cho thấy sai số lớn nhất là $0,155 \mathrm{~m}$ tại lỗ khoan CHD3-1, sai số nhỏ nhất là $0,011 \mathrm{~m}$ tại lỗ khoan CHD3-2, sai số trung bình là $0,095 \mathrm{~m}$ và sai số trung bình tuyệt đối là $0,095 \mathrm{~m}$ (Hình 7). 


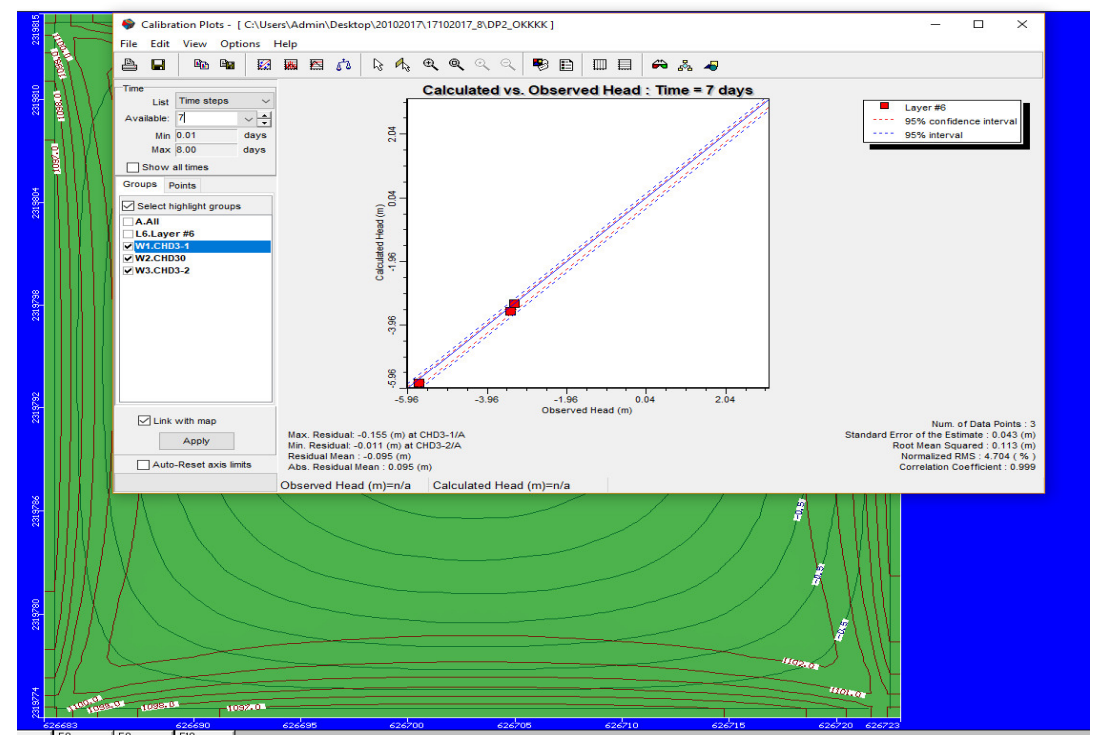

Hình 7. Đồ thị chỉnh lý mực nước.

\subsubsection{Kết quả chỉnh lý mô hình dịch chuyển vật chất}

Dựa trên kết quả thí nghiệm đổ muối để tiến hành chỉnh lý các thông số về độ lỗ hổng hữu hiệu, các hệ số phân tán, tỷ số khuếch tán dọc và khuếch tán ngang. Tại chùm thí nghiệm CHD3 đã tiến hành ép dung dịch muối ăn lỗ khoan CHD3-2, trên cơ sở đó thiết lập các thông số cho mô hình như sau:

- Các điều kiện biên nồng độ của nguồn gây ô nhiễm

Nồng độ không đổi tại lỗ khoan CHD3-1 với EC=2500mg/l được thể hiện trên Hình 8.

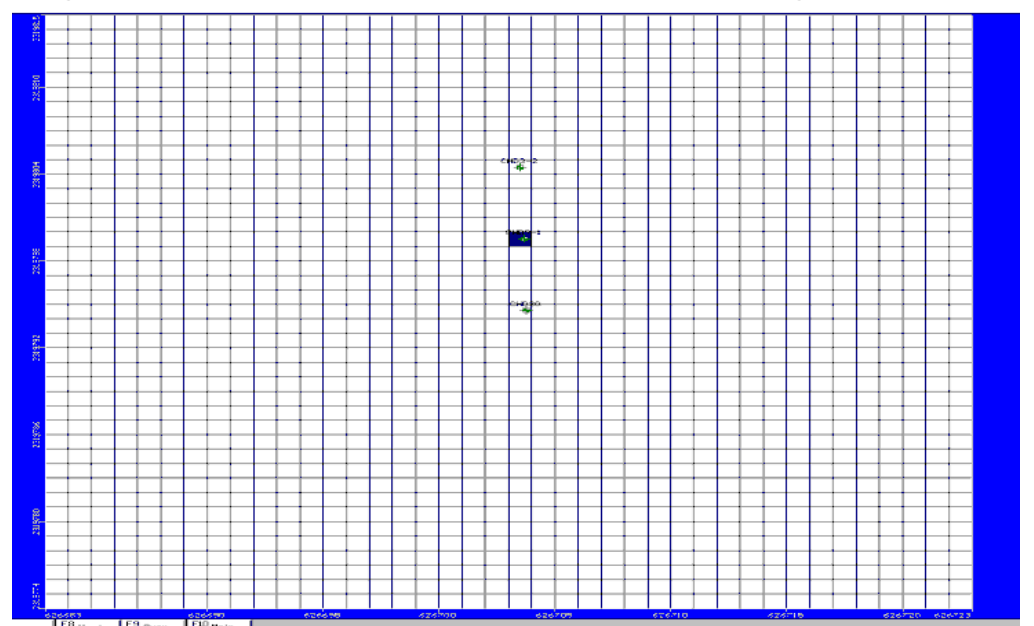

Hình 8. Gán biên nồng độ không đổi cho nguồn gây ô nhiễm.

Đối với điều kiện biên nồng độ ban đầu của tầng chứa nước lựa chọn nồng độ trung bình $\mathrm{EC}_{0}=1200 \mathrm{mg} / \mathrm{l}$.

Điều kiện biên bổ cập của mưa cho tầng chứa nước $\mathrm{EC}=0 \mathrm{mg} / \mathrm{l}$.

- Các thông sên bổ cập của mưa cho tầng chứa nước $\mathrm{EC}=0 \mathrm{mg} / 1$

Các thông số về hệ số phân tán thủy động lực trong mô hình được lựa trọn như sau:

+ Tỷ số giữa hệ số phân tán ngang/ hệ số phân tán dọc lấy bằng 0,1 (hay nói cách khác là hệ số phân tán dọc $\alpha_{\mathrm{L}}=10 \alpha_{\mathrm{T}}$ ).

$+\mathrm{D}_{\mathrm{d}}$ là hệ số khuyếch tán phân tử trong cát, cuội, sỏi theo các hướng dẫn chuyên môn là $0,3-0,7 \times 10^{-5} \mathrm{~cm}^{2} / \mathrm{s}$, lựa chọn $\mathrm{D}_{\mathrm{d}}=0,0017 \mathrm{~m}^{2} /$ ngày. 
Bảng 2. Các thông số dịch chuyển của mô hình.

\begin{tabular}{ccccc}
\hline Lớp & $\begin{array}{c}\text { Hệ số phân tán } \\
\text { ngang }\left(\boldsymbol{\alpha}_{\mathrm{L}}\right)\end{array}$ & $\begin{array}{c}\text { Hệ số phân tán } \\
\text { dọc }\left(\boldsymbol{\alpha}_{\mathrm{T}}\right)\end{array}$ & $\begin{array}{c}\text { Hệ số khuyếch tán } \\
\text { phân tử (m2/ngày) }\end{array}$ & $\begin{array}{c}\text { Ghi } \\
\text { chú }\end{array}$ \\
\hline 1 & 0,1 & 0,01 & 0,00011232 \\
2 & 0,1 & 0,01 & 0,00011232 \\
3 & 0,1 & 0,01 & 0,00011232 \\
4 & 0,1 & 0,01 & 0,00011232 \\
5 & 0,1 & 0,01 & 0,00011232 \\
6 & 0,1 & 0,08 & 0,0017 \\
7 & 0,1 & 0,01 & 0,00011232 \\
\hline
\end{tabular}

- Khuyếch tán phân tử ( $\mathrm{m}^{2} /$ ngày) h.t, cuội,

Chỉnh lý mô hình dịch chuyển vật chất tiến hành dựa theo tài liệu quan trắc nồng độ $\mathrm{EC}$ tại các các lỗ khoan quan sát. Mức độ tin cậy của mô hình được xác định qua sai số mực nước giữa mô hình và lỗ khoan quan sát thực tế (Hình 9).

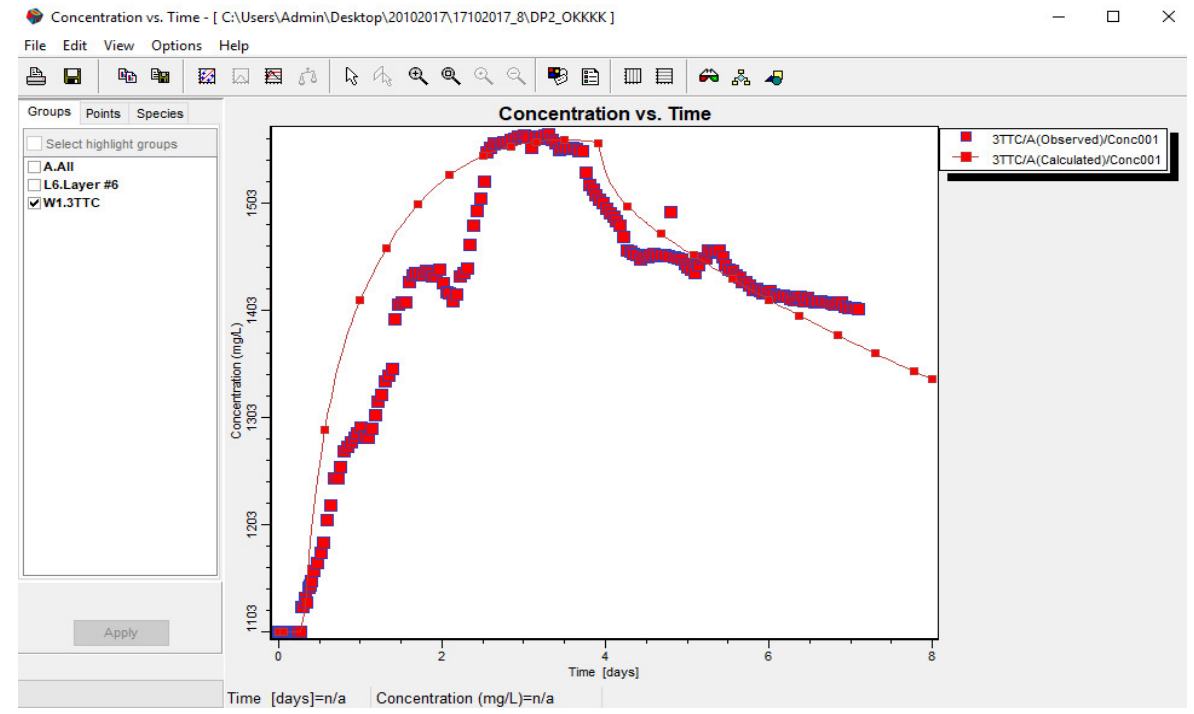

Hình 9. Đồ thị chỉnh lý nồng độ EC tại lỗ khoan CHD3.

Theo kết quả nghiên cứu [16-20] thì độ lỗ rỗng tổng cộng của cát và cuội sỏi có độ chọn lọc tốt là $0,25-0,5$ và của cát lẫn cuội sởi là $0,2-0,35$. Đối với đất đá bở rời hạt thô độ lỗ rỗng hữu hiệu có giá trị tương đương với độ lỗ rỗng toàn phần do không có sự tồn tại của các lỗ rỗng không thông nhau. Vì vậy giá trị độ lỗ rỗng hữu hiệu bằng 0,23 xác định được bằng phương pháp trình bày trong bài viết theo kết quả thí nghiệm là phù hợp, không có sự mâu thuẫn, nằm trong giới hạn các giá trị thực đối với cát cuội sỏi tầng chứa nước Pleistocen.

\section{Kết luận}

Từ kết quả phân tích số liệu thí nghiệm hiện trường và mô phỏng, hiệu chỉnh bằng phương pháp mô hình số dòng chảy Modlfow và dịch chuyển chất bẩn MT3D đã xác định thông số lan truyền độ lỗ rỗng hữu hiệu tầng chứa nước qp1 rút ra một số kết luận như sau:

- Qua phân tích, sử dụng mô hình số Modflow + MT3D và các kết quả thí nghiệm hiện trường là công cụ tốt để xác định độ lỗ rỗng hữu hiệu các tầng chứa nước lỗ hổng phục vụ dự báo mức độ nhiễm mặn nước dưới đất.

- Với việc thí nghiệm và quan trắc nồng độ chất chỉ thị muối ăn $(\mathrm{NaCl})$ trong $\mathrm{LK}$ hút nước phù hợp với thực tế khu vực nghiên cứu để đánh giá đỗ lỗ hữu hiệu của tầng chứa nước; 
- Phương pháp mô hình số lan truyền chất hoà tan trong NDĐ và xác định thông số theo phương pháp tổng hiệu bình phương là rất hiệu quả trong các bài toán này;

- Kết quả nghiên cứu ở khu vực Hải Dương đã xác định độ lỗ rỗng hữu hiệu tầng chứa nước qp1 là 0,23 rất phù hợp, không có sự mâu thuẫn, nằm trong giới hạn các giá trị thực đối với cát cuội sỏi tầng chứa nước Pleistocen.

Đóng góp cho nghiên cứu: Xây dựng ý tưởng nghiên cứu: H.V.D.; Lựa chọn phương pháp nghiên cứu: H.V.D., T.T.T.; Thu thập, phân tích, xử lý số liệu: H.V.D., N.T.H.; Viết bản thảo bài báo: H.V.D., N.T.H.; Chỉnh sửa bài báo: Đ.T.H.

Lò̀i cảm ơn: Bài báo này được hoàn thành trong khuôn khổ thực hiện Đề tài nghiên cứu theo Nghị định thư giữa Bộ Khoa học Công nghệ Việt Nam và Bộ Nghiên cứu và giáo dục Cộng hòa liên bang Đức, "Nghiên cứu ứng dụng và phát triển công nghệ khai thác nước thấm từ sông ở Việt Nam phục vụ sinh hoạt và sản xuất”, mã số đề tài 60.GER-19.

Lời cam đoan: Tập thể tác giả cam đoan bài báo này là công trình nghiên cứu của tập thể tác giả, chưa được công bố ở đâu, không được sao chép từ những nghiên cứu trước đây; không có sự tranh chấp lợi ích trong nhóm tác giả.

\section{Tài liệu tham khảo}

1. Tùng, T.T. và cs. Báo cáo kết quả dự án: Bảo vệ nước dưới đất ở các đô thị lớn - Đô thị Hải Dương. Lưu trữ Cục Quản lý tài nguyên nước, 2016.

2. Quỳnh, C.V. và cs. Báo cáo điều tra địa chất đô thị thành phố Hải Dương. Lưu trữ Liên đoàn Quy hoạch và Điều tra tài nguyên nước miền Bắc, Hà Nội, 1999.

3. Quỳnh, C.V. và cs. Báo cáo kết quả thăm dò tỷ mỷ nước dưới đất vùng Cẩm Giàng, Hải Dương - Mỹ Văn, Hưng Yên, Lưu trữ Cục Quản lý tài nguyên nước, Hà Nội, 1997.

4. Tuyển, C.T. và cs. Báo cáo tìm kiếm nước dưới đất vùng Văn Lâm - Văn Giang tỉ lệ 1:50.000, Lưu trữ Liên đoàn Quy hoạch và Điều tra tài nguyên nước miền Bắc, Hà Nội, 1990.

5. Bốn, C.V. và cs. Báo cáo tìm kiếm nước dưới đất vùng Nam Sách - Hải Hưng tỉ lệ 1:25.000, Lưu trữ Liên đoàn Quy hoạch và Điều tra tài nguyên nước miền Bắc, Hà Nội, 1982.

6. Quyền, P.B. và cs. Báo cáo Điều tra, đánh giá tài nguyên nước vùng thủ đô Hà Nội, 2016.

7. Hoàng, N.V. Mô hình lan truyền chất ô nhiễm trong môi trường nước. Nhà xuất bản Viện Hàn lâm Khoa học và Công nghệ Việt Nam, Hà Nội, 2018.

8. Hoàng, N.V. Nghiên cứu xây dựng phần mềm mô hình phần tử hữu hạn mô phỏng chuyển động và lan truyền các chất ô nhiễm và nhiễm mặn trong môi trường nước dưới đất-ứng dụng cho khu vực ven biển miền Trung, 2017.

9. Thanh, T.N. và cs. Phương pháp luận xác định độ lỗ rỗng hữu hiệu và độ phân tán tầng chứa nước áp dụng cho thí nghiệm hiện trường tại phía Nam Hà Nội, 2018.

10. Hạ, N.T. Sự hình thành thành phần hóa học tầng chứa nước Pleistocen vùng Đồng Bằng Bắc Bộ, 2001.

11. Hạ, N.T. Sự hình thành thành phần hóa học nước dưới đất trong trầm tích Đệ tứ vùng đồng bằng Bắc bộ và ý nghĩa của nó đối với cung cấp nước, 2006.

12. Duy, K. Nghiên cứu tác động do biến đổi khí hậu và nước biển dâng đến xâm nhập mặn các tầng chứa nước ven biển trầm tích Đệ Tứ và đề xuất các giải pháp thích ứng 
vùng Hậu Lộc, tỉnh Thanh Hóa, 2015.

13. Quy, $\mathrm{P} . \mathrm{N}$ và cs. Lựa chọn khai thác tối ưu nhằm tránh xâm nhập mặn đối với các lỗ khoan khai thác nước dưới đất các tầng chứa nước ven biển, lấy vị dụ vùng tỉnh Ninh Thuận, 2020.

14. Tường, P.V. Đặc điểm thủy địa hóa và thực trạng nhiễm mặn nước dưới đất trong các trầm tích Đệ Tứ vùng ven biển Hà Tĩnh, 2014.

15. Bảng, P.V. Nước dưới đất vùng đồng bằng Bắc bộ. 1984.

16. Mantoglou, A. Pumping management of coastal aquifers using analytical models of saltwater intrusion. Water Resour. Res. 2003, 391(12), 1335.

17. Brouyère, S. Modeling tracer injection and well-aquifer interactions: a new mathematical and numerical approach. Hydrogeology, Department of Georesources, Geotechnologies and Building Materials, University of Liège, Building B52, 4000 Sart Tilman, Belgium, 2008.

18. Bear, J.; Verruijt, A. Modeling groundwater flow and pollution. D. Reidel Publishing Company, Dordrecht, Holand, 1987.

19. Fetter, C.W. Applied Hydrogeology. Prentice Hall Inc. New Jersey 07458, 2001.

20. Zlotnik, V.A.; Logan, J.D. Boundary Conditions for Convergent Radial Tracer Tests and Effect of Well Bore Mixing Volume. Water Resour. Res. 1996, 32(7), 23232328. https://doi.org/10.1029/96wr01103.

\title{
Ditermining the effective porosity of Pleistocene aquifer at Cam Hoang - Hai Duong by using experiment methods and numerical models
}

\author{
Hoang Van Duy ${ }^{1}$, Nguyen Trung Hieu², Tong Thanh Tung ${ }^{3}$, Doan Thu Ha ${ }^{*}$ \\ ${ }^{1}$ Institute of Water Resources Science; hoangduydctv@gmail.com \\ 2 Thuyloi University; trunghieu.ma@hotmail.com \\ ${ }^{3}$ Divison of Northern Water Resources Planning and Investigation; \\ thanhtungtv51@gmail.com \\ ${ }^{4}$ Thuyloi University; thuha_ctn@tlu.edu.vn
}

\begin{abstract}
The effective porosity $\left(\mathrm{n}_{0}\right)$ is one of the important specialized hydrogeological parameters, which are significant in determining the fast or slow transmission of polluting and saline substances in groundwater. In Hai Duong area, the groundwater salinity level is very complicated, the groundwater quantity extraction increases over time, which is the cause of saline intrusion. Effective porosity of 0.23 was determined for saline-pale boundary area at Cam Hoang-Hai Duong Pleistocene aquifer $\left(\mathrm{qp}_{1}\right)$ by using pumping and salt pressing experiment methods and the Modflow and MT3D models.
\end{abstract}

Keywords: Salinity; Laboratory water absorption; Indicator solution; Effective porosity; Numerical model. 